\author{
INTERNATIONAL UNION OF PURE \\ AND APPLIED CHEMISTRY \\ COMMISSION ON QUANTITIES AND UNITS \\ IN CLINICAL CHEMISTRY \\ INTERNATIONAL FEDERATION \\ OF CLINICAL CHEMISTRY \\ EXPERT PANEL ON QUANTITIES AND UNITS
}

\title{
QUANTITIES AND UNITS IN CLINICAL CHEMISTRY
}

\author{
(Recommendations 1978) \\ Prepared for publication by \\ R. DYBKAER \\ Frederiksberg Hospital, \\ Copenhagen, Denmark
}




\title{
INTERNATIONAL UNION OF PURE AND APPLIED CHEMISTRY AND INTERNATIONAL FEDERATION OF CLINICAL CHEMISTRY
}

\author{
IUPAC SECTION ON CLINICAL CHEMISTRY \\ COMMISSION ON QUANTITIES AND UNITS IN CLINICAL CHEMISTRY \\ and
}

IFCC COMMITTEE ON STANDARDS

EXPERT PANEL ON QUANTITIES AND UNITS

APPROVED RECOMMENDATION (1978)

QUANTITIES AND UNITS IN CLINICAL CHEMISTRY

Prepared for publication by

R. Dybkær

Department of Clinical Chemistry, Frederiksberg. Hospital, Nordre Fasanvej 59, DK-2000 Copenhagen $F$, Denmark

\section{Preface}

The Commission on Quantities and Units in Clinical Chemistry * is a part of the Section on Clinical Chemistry of the International Union of Pure and Applied Chemistry (IUPAC). The Expert Panel on Quantities and Units ** is a part of the Committee on Standards of the International Federation of Clinical Chemistry (IFCC). These two bodies, the Commission and the Expert Panel, have worked on this document, the former mainly concerned with basic philosophy, the latter with problems of implementation.

The aim has been to bring clinical chemical nomenclature into line with evolving international scientific language, especially by drawing upon the recommendations of the International Committee of Weights and Measures, the

\footnotetext{
* Titular members: B.H. Ambrecht (Beltsville, U.S.A.) 1967-1975; R. Dybkær (Copenhagen, Denmark) 1967-1977 (Chairman 1967-1975); R. Herrmann (Giessen, German Federal Republic) 1971-1979; K. Jфrgensen (Copenhagen, Denmark) 1967-1973; P. Métais (Strasbourg, France) 1967-1975; J.C. Rigg (Wageningen, The Netherlands) 1973-1977; O. Siggaard-Andersen (Copenhagen, Denmark) 1975-1979; R. Zender, Chairman (La Chaux-de-Fonds, Switzerland) 1975-1979.

Associate members: B.H. Armbrecht (Beltsville, U.S.A.) 1975-1979; K. J $\phi$ rgensen (Copenhagen, Denmark) 1975-1979; P. Métais (Strasbourg, France) 1975-1979.

** Titular members: as above.
} 
International Union of Biochemistry, the Technical Committee 12 of the International Organization for Standardization, and, of course, IUPAC (see References).

The tentative version of the present publication appeared as an IUPAC-IFCC (yellow) Information Bulletin, Appendices on Tentative Nomenclature, Symbols, Units, and Standards, No. 20, February 1972. As a consequence of later decisions by international bodies concerned with nomenclature, a considerable number of comments, and new deliberations by the Commission and Expert Panel (see Appendix), a Recommendation 1973 contained many, mostly small, modifications from the tentative version. The Recommendation 1973 was approved by IUPAC in 1973 and published in Pure and Applied Chemistry 1974, 37, 517-546. The IFCC Council in 1975 did not accept the text on account of another view on quantities and units in enzymology presented in the IFCC Expert Panel on Enzymes' Provisional Recommendation (1974) [13]. At a joint meeting in Strasbourg 1976 the Expert Panel on Quantities and Units, the Commission on Quantities and Units in Clinical Chemistry, and the Expert Panel on Enzymes reconciled their concepts, which were further modified according to the advice of the IUPAC Interdivisional Committee on Nomenclature and Symbols. The present document incorporates the resulting changes in names and definitions of kinds of quantities in enzymology.

Where it conflicts, the present document supersedes the larger IUPAC-IFCC Recommendation 1966, its translation into Spanish, and the IUPAC Recommendation 1973.

This Recommendation has been approved by IUPAC and by IFCC 1978 .

\section{Contents}

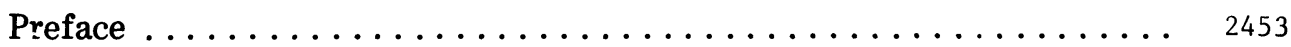

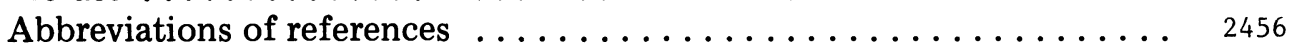

1. Introduction . . . . . . . . . . . . . . . . . . . 2456

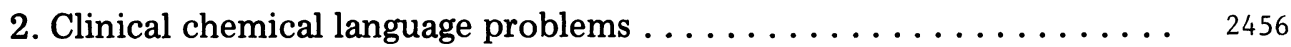

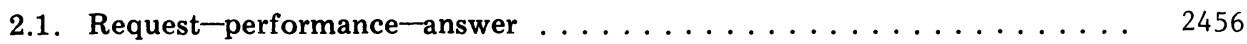

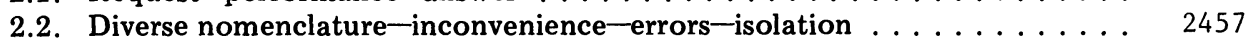

2.3. Recommendation 1966 of CCC (IUPAC) and IFCC . . . . . . . . . . 2457

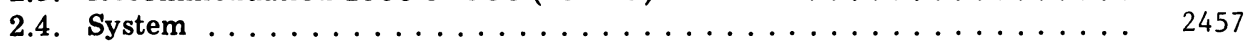

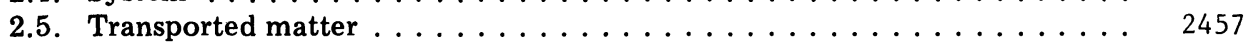

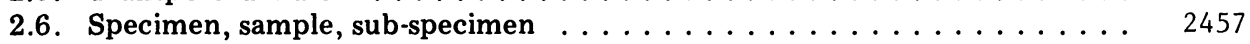

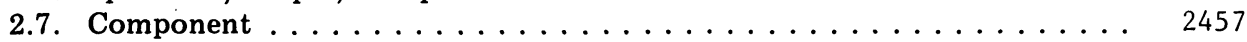

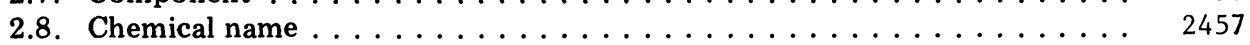

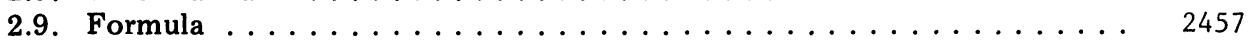

2.10. Elementary entity (formula unit, elementary unit) . . . . . . . . 2457

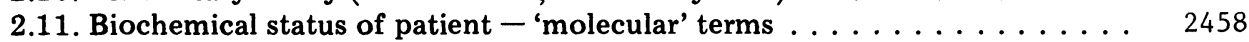

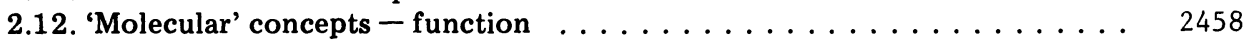

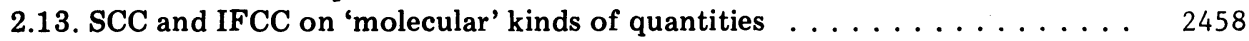

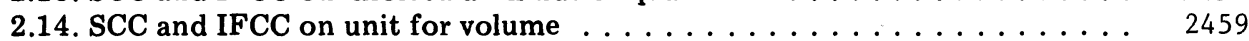

3. Definitions of fundamental concepts of quantities . . . . . . . . . . . 2459

3.1. Quantity . . . . . . . . . . . . . . . . . . . . . . . . 2459

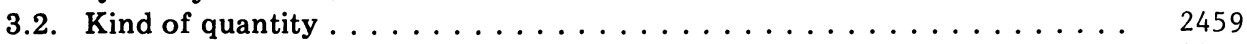

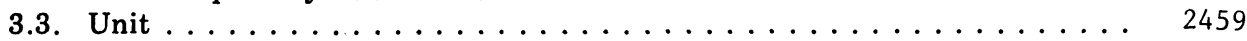

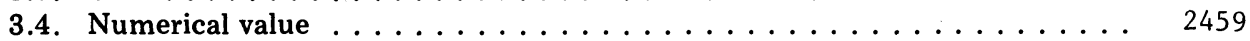

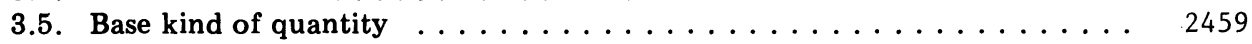




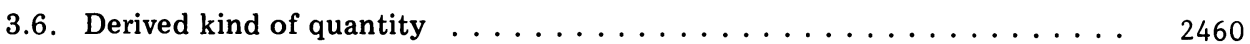

3.7. Dimension of quantity . . . . . . . . . . . . . . . . . . . . . . . 2460

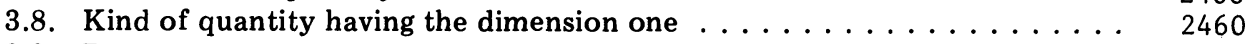

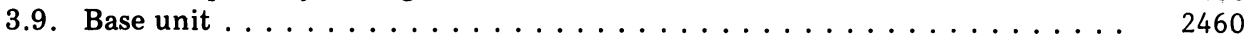

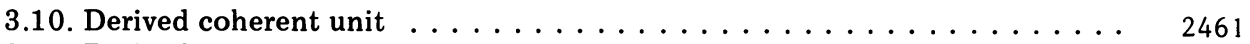

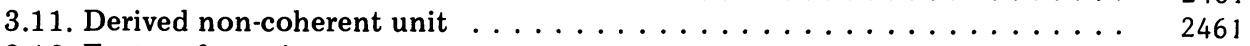

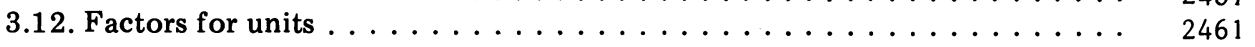

4. Kinds of quantities and units ...................... 2461

4.0. Organization of material in Section $4 \ldots \ldots \ldots \ldots \ldots \ldots$

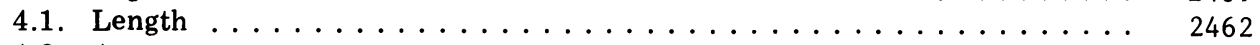

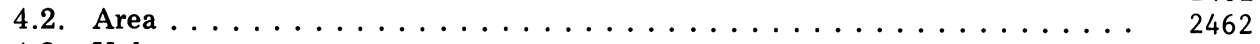

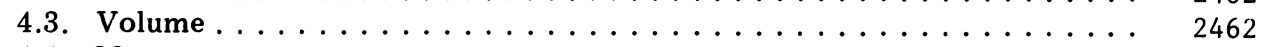

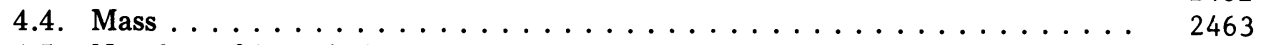

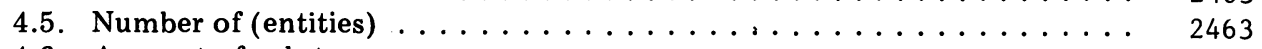

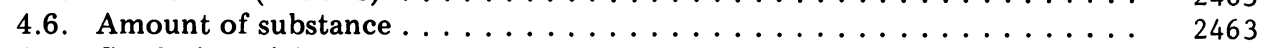

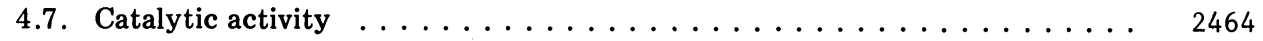

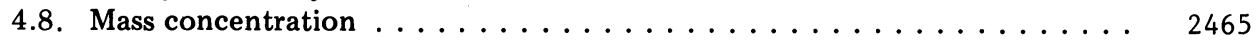

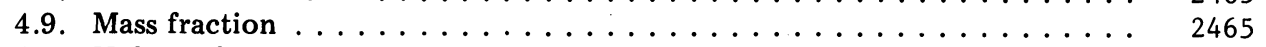

4.10. Volume fraction . . . . . . . . . . . . . . . . . . . . . . 2466

4.11. Substance concentration ('molar concentration') . . . . . . . . . . . 2466

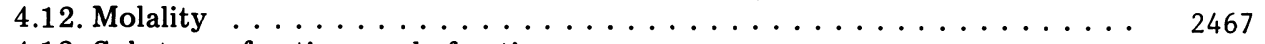

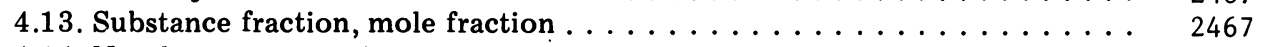

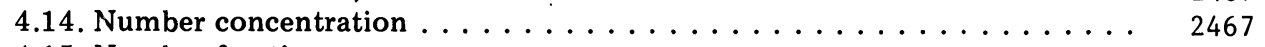

4.15 Number fraction . . . . . . . . . . . . . . . . . . . . . . . . . . . 2468

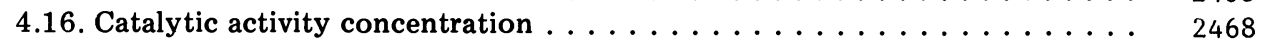

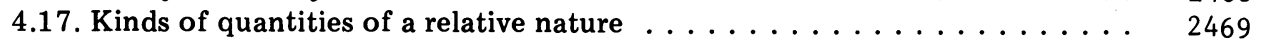

4.18. Thermodynamic temperature ..................... 2469

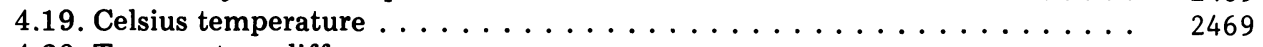

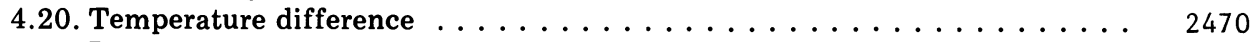

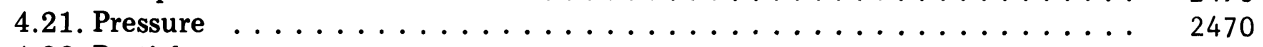

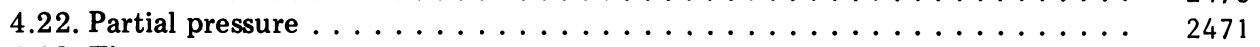

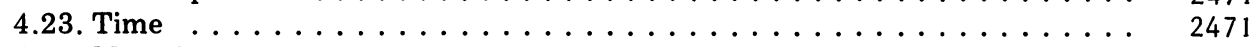

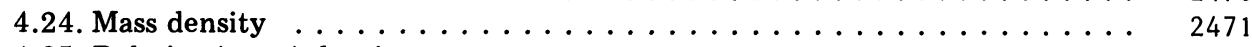

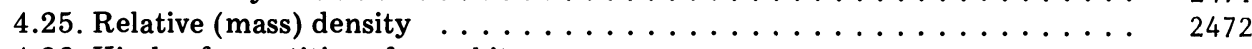

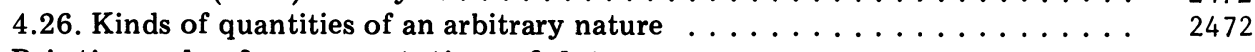

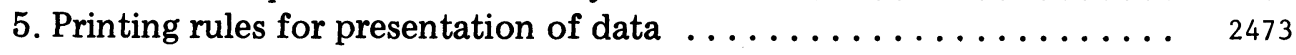

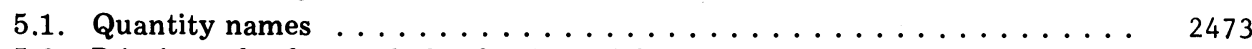

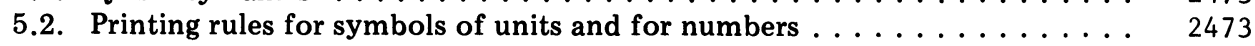

6. Proposed new derived kinds of quantities . . . . . . . . . . . . . . . . 2474

6.0. Development of new kinds of quantities . . . . . . . . . . . . . . . . . . . 2474

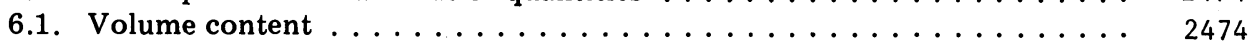

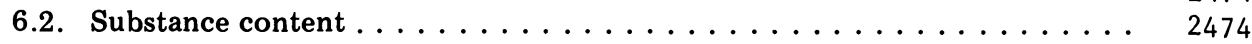

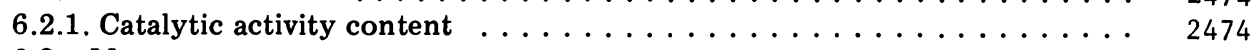

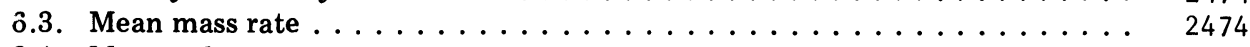

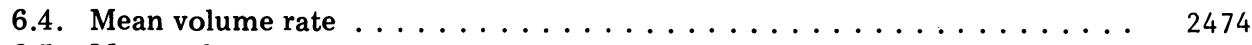

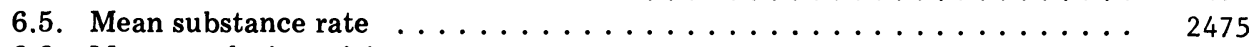

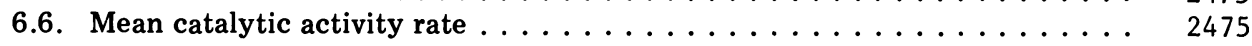

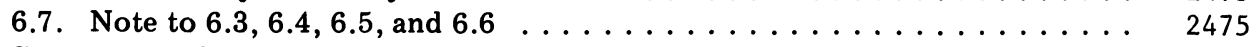

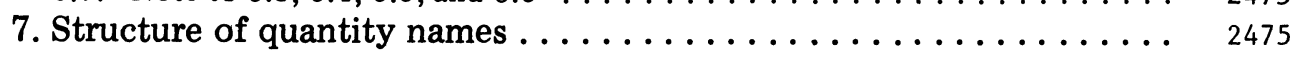

7.1. Recommendation 1966 on structure of quantity names . . . . . . . . . 2475

7.2. Convention for joining System-Component, kind of quantity . . . . . . . 2475

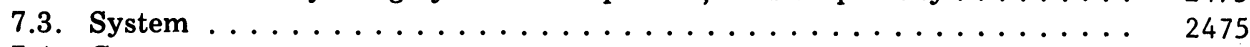

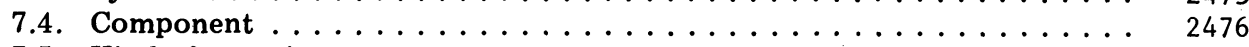

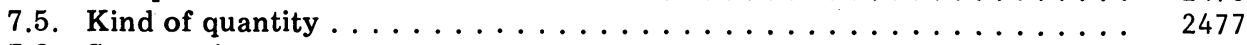

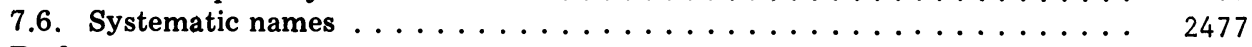

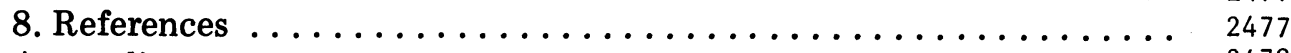

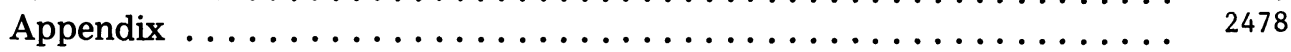




\section{Abbreviations of references}

\begin{tabular}{|c|c|}
\hline $\mathrm{BN}$ & Commission on Biochemical Nomenclature (IUPAC-IUB) \\
\hline $\mathrm{CCC}$ & Commission on Clinical Chemistry (IUPAC, before 1967) \\
\hline CGPM & Conférence Générale des Poids et Mesures \\
\hline CQUCC & $\begin{array}{l}\text { Commission on Quantities and Units in Clinical Chemistry (IUPAC; } \\
\text { after 1967) }\end{array}$ \\
\hline PQU & $\begin{array}{l}\text { Expert Panel on Quantities and Units (IFCC Committee on Stan- } \\
\text { dards) }\end{array}$ \\
\hline ICSH & International Committee for Standardization in Hematology \\
\hline IFCC & International Federation of Clinical Chemistry \\
\hline ISO & International Organization for Standardization \\
\hline IUB & International Union of Biochemistry \\
\hline IUPAC & International Union of Pure and Applied Chemistry \\
\hline QU-R66 & $\begin{array}{l}\text { Quantities and Units in Clinical Chemistry. Recommendation } 1966 \\
\text { (IUPAC-IFCC) }\end{array}$ \\
\hline QU-R73 & $\begin{array}{l}\text { Quantities and Units in Clinical Chemistry. Recommendation } 1973 \\
\text { (IUPAC) }\end{array}$ \\
\hline & Section on Clinical Chemistry (IUPAC) \\
\hline W & n of (Anatomic and Clinical) Pathology Societies \\
\hline
\end{tabular}

\section{Introduction}

Recommendation 1966 of the Commission on Clinical Chemistry of the International Union of Pure and Applied Chemistry and of the International Federation for Clinical Chemistry [4] was published in 1967. This was the first effort of international organizations towards a rationally standardized presentation of chemical data from clinical laboratories.

At the IUPAC Conference in Prague in 1967, the newly created Section on Clinical Chemistry nominated a Commission on Quantities and Units in Clinical Chemistry (see footnote * on p. 2453). This body was joined in 1968 by the Expert Panel on Quantities and Units created by the Committee on Standards of the International Federation of Clinical Chemistry (see footnote ** to p.2453). One common task was the supervision of short versions of the Recommendation 1966 [4] = QU-R66. The present publication contains such a revised condensation in Sections 3,4 and 5 which are now the official version in cases of conflict. Chemical background material is given in Section 2. Section 6 corresponds to the QU-R66 Part 5 with new kinds of quantities. Section 7 contains examples of clinical chemical quantities in a new generic form, which is further elaborated in a separate publication 'List of Quantities. Approved Recommendation 1978' (pp. 2481-2502).

The kinds of quantities treated in this document do not by far cover all aspects of clinical chemical work. It is hoped that additional recommendations will be prepared to alleviate this defect.

\section{Clinical chemical language problems}

2.1. The main task of the clinical chemist is the measurement of the chemical, biochemical, and sometimes physical properties of patients. These data are 
used by the clinician for diagnostic and therapeutic purposes. It is of paramount importance, therefore, that the determinations requested by the clinician are those performed by the laboratory and that each answer is understood correctly by the clinician.

In order to avoid misunderstandings a set of rules must be observed during transmission, i.e. the 'language' must be standardized.

2.2. Traditionally, there has been no accepted usage for the request and presentation of data, be it on the international, national or local level. This has been inconvenient, time-consuming and, in some instances, dangerous to the patient.

Another, very unfortunate result of the diverse - and often quaint - usages in clinical chemistry is a barrier of incomprehensibility between this discipline and the rest of science where chemistry, biochemistry, and physics have cooperated on a standardized language for some years.

2.3. The international clinical chemical bodies now try to eliminate the language part of the barrier by adopting pertinent parts of the communication language constructed by related international science bodies. The Recommendation 1966 by CCC of IUPAC and IFCC is updated and summarized in Sections 3 and 4 ; to understand them, some chemical concepts are recapitulated.

2.4. The clinical chemical description of a patient requires initially the selection of a system, which may be arbitrarily chosen. Examples: the patient as such, his liver, blood, thrombocytes, hemoglobin.

2.5. Transported matter to or from the system may be regarded as a component or group of components entering or leaving the system or can be considered a separate chemical system. Examples: food absorbed, urine excreted, blood supplied to the liver.

2.6. In clinical chemistry, it is usually convenient or necessary to refrain from using the entire system for measurement; instead a specimen is obtained, i.e. a representative part of a system or, at least, a part obtained by a standardized procedure. Examples: specimens of 24-h urine, of venous blood, of serum from venous blood. The actual measurement is often on a representative subspecimen.

2.7. A chemically definable substance in the form of atoms, molecules or ions is called a chemical component of the system. Examples: helium, water, and sodium ion respectively.

2.8. The chemical name, if practical and possible, should be a fully specified systematic name, preferably constructed according to IUPAC rules. Examples: carbamide rather than urea, sodium ion (not 'sodium').

2.9. The formula for a molecule or an ion is a symbolic representation indicating the atoms (and charges, if any) involved in the entity. Examples:

$\mathrm{H}_{2} \mathrm{O}$ (sterically ${ }^{\mathrm{H}} \backslash \mathrm{O}^{-}{ }^{\mathrm{H}}$ ), $\mathrm{CH}_{3} \mathrm{COOH}, \mathrm{SO}_{4}^{2-}$

2.10. For complicated molecules or where a name alone may signify more species of particles than intended, it is necessary to supply an elementary entity (a formula unit or elementary unit), i.e. a chemical symbol indicating a relevant repetitive structure of the chemical component. Examples: $\mathrm{N}_{2}, \mathrm{~N}, \mathrm{Ca}^{2+}, \mathrm{COOH}$ (carboxyl), $\mathrm{H}_{2} \mathrm{O}, \mathrm{C}_{6}$. 
2.11. One goal of the clinical chemical description is to furnish information on the patient's biochemical status, be it normal or pathological. The chemical processes taking place in a living organism are governed by well-known laws, which are formulated in 'molecular' terms. Consequently, clinical chemical measurements of amounts of components or their concentrations should preferably be expressed with reference to the groups of atoms, molecules or ions participating.

2.12. An evident advantage for clinical chemistry of the 'molecular' concepts (see 2.13) was realized rather early for some inorganic electrolytes: sodium ion, potassium ion, chloride, and hydrogen carbonate. To-day, the concentrations of these components are usually given as 'molar concentrations' in millimoles per litre (or 'milliequivalents per litre'). For many organic and some inorganic substances, however, mass concentration is widely used, often with a volume of 100 millilitres (of solution) as denominator in the unit.

Mass concentration rarely yields biologically useful information; in fact, biological relationships are obscured and, consequently, not often contemplated. In contrast, 'molecular' concepts immediately expose functional relationships. A few series of interdependent components * might suffice to illustrate this fact:

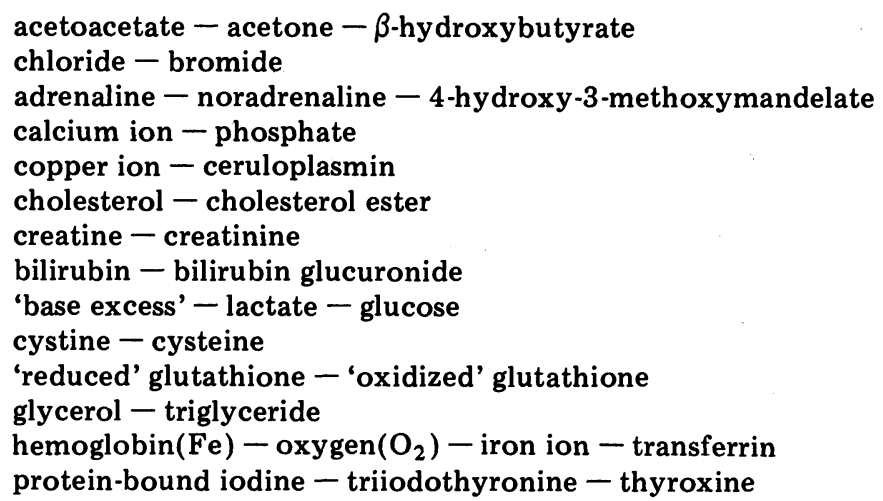

2.13. SCC and IFCC recommend that kinds of quantities of a 'molecular' nature should be used whenever an elementary entity can be defined for a component, be it an electrolyte or a non-electrolyte, inorganic or organic, and whatever its size.

Consequently, of the kinds of quantities listed in Section 4, the following are preferable when describing 'amount' or 'concentration' of matter. amount of substance (mole)

instead of mass (kilogram),

substance concentration $* *$ (mole per litre)

instead of mass concentration (kilogram per litre), substance fraction (also called mole fraction) (unity)

instead of mass fraction (unity), volume fraction (unity), and molality (mole per kilogram).

\footnotetext{
* The names listed accord with current usage and are not those used in 'List of Quantities. Approved Recommendation 1978'.

** See 4.11.6
} 
This recommendation is supported jointly by the 1972 Recommendation from ICSH, IFCC and WAPS [6].

2.14. The Recommendation 1966 states that the litre is the preferred unit for volume (see [3], Note 2) in expressing concentration in liquids and solids, where volume is the denominator. The present arbitrary use of microlitre, millilitre, decilitre (= 100 millilitres), and litre repeatedly results in recalculations and consequent errors.

\section{Definitions of fundamental concepts of quantities}

3.1. Quantity: a measurable, real property, physical or chemical, of a specified system. Example: substance concentration of glucose in the blood plasma of a stated patient.

3.2. Kind of quantity: the abstract concept of the property, common to a number of real phenomena (quantities). Examples: length, substance concentration, pressure.

Note: ISO, IUPAC, and IUPAP employ the term 'quantity' both for the abstract, 'non-addressed' concept of, e.g., substance concentration and for the 'addressed' measurable property given in 3.1.

3.3. Unit: a chosen reference quantity, which may be used for comparison of quantities of the same dimension. Examples: millimetre (e.g. for lengths), kilogram (e.g. for masses), mole (e.g. for amounts of substance), gram per litre (e.g. for mass concentration or mass densities).

Note: The magnitude of the quantity is not influenced by the choice of unit.

3.4. Numerical value: the number that gives the magnitude of the measured quantity when multiplied by the unit.

Numerical value $=$ quantity $/$ unit

Note 1. The magnitude of a quantity should not be expressed as a numerical value alone, except perhaps for quantities having the dimension one, see 3.8. Example: Substance concentration of sodium ion in a specified serum is not ' 139 ' but ' 139 millimoles per litre'. The relative density of the same serum could be adequately expressed as 1,026 , but the unit ' 1 ' can be stated: $1,026 \times 1$.

Note 2. The 'equal to' sign does not allow inference of the kind of quantity involved from inspection of the unit employed. Example: The unit, gram per litre, is common to measurements of mass concentration and mass density.

Note 3. The meaning of the numerical value is a statistical analytical problem beyond the scope of this document. In general, it is advisable to supply information about analytic variation and reference values ('normal values').

3.5. Base kind of quantity: a kind of quantity considered dimensionally independent of other base kinds of quantities, i.e. it is not defined by an equation containing other kinds of quantities. Examples: length, mass, amount of substance.

Note. Base quantities are chosen arbitrarily but according to a practical plan. The seven base kinds of quantities corresponding to the International System of Units (SI units) are shown in Table I (3.5) [12]. 
TABLE I (3.5)

BASE KINDS OF QUANTITIES AND SI BASE UNITS

\begin{tabular}{lllll}
\hline Name & Symbol & Dimension & Name & Symbol \\
\hline Length & $l$ & $\mathrm{~L}$ & metre & $\mathrm{m}$ \\
Mass & $m$ & $\mathrm{M}$ & kilogram & $\mathrm{kg}$ \\
Time & $t$ & $\mathrm{~T}$ & second & $\mathrm{s}$ \\
Electric current & $I$ & $\mathrm{I}$ & ampere & $\mathrm{A}$ \\
Thermodynamic temperature & $T$ & $\Theta$ & kelvin & $\mathrm{K}$ \\
Luminous intensity & $I$ & $\mathrm{~J}$ & candela & $\mathrm{cd}$ \\
Amount of substance & $n$ & $\mathrm{~N}$ & mole & $\mathrm{mol}$ \\
\hline
\end{tabular}

3.6. Derived kind of quantity: a kind of quantity characterized by an equation between base kinds of quantities. Example: mass concentration = mass/ (length) ${ }^{3}$.

3.7. Dimension of quantity. Any (kind of) quantity can be analysed into a product of dimensional factors, one for each of the dimensions, corresponding to the seven base kinds of quantities. Example: Mass concentration and density both have the dimension $\mathrm{L}^{-3} \mathrm{M}^{1} \mathrm{~T}^{0} \mathrm{I}^{0} \Theta^{0} \mathrm{~J}^{0} \mathrm{~N}^{0}=\mathrm{ML}^{-3}$, they are equidimensional; the appropriate units $\mathrm{mg} / \mathrm{l}, \mathrm{g} / \mathrm{l}, \mathrm{kg} / \mathrm{m}^{3}$, etc. have the same dimension.

3.8. Kind of quantity having the dimension one (1): Examples: Number (of entities), mass fraction, relative density all have the dimension $\mathrm{L}^{0} \mathrm{M}^{0} \mathrm{~T}^{0} \mathrm{I}^{0} \Theta^{0} \mathrm{~J}^{0} \mathrm{~N}^{0}=$ 1. (Such kinds of quantities are often called 'dimensionless'.)

3.9. Base unit: a unit defined for a base kind of quantity. Examples: metre, kilogram, mole. See Table I (3.5).

TABLE II (3.12)

SI PREFIXES DENOTING DECIMAL FACTORS

\begin{tabular}{|c|c|c|c|}
\hline Factor & Prefix & Symbol & \\
\hline $10^{18}$ & exa & $\mathbf{E}$ & \\
\hline $10^{15}$ & peta & $\mathbf{P}$ & - \\
\hline $10^{12}$ & tera & $\mathbf{T}$ & . \\
\hline $10^{9}$ & giga & $\mathrm{G}$ & \\
\hline $10^{6}$ & mega & $\bar{M}$ & \\
\hline $10^{3}$ & kilo & $\mathbf{k}$ & \\
\hline $10^{2}$ & hecto & h & \\
\hline $10^{1}$ & deca & $\mathrm{da}$ & \\
\hline $10^{-1}$ & deci & d & \\
\hline $10^{-2}$ & centi & c & \\
\hline \multicolumn{4}{|c|}{ 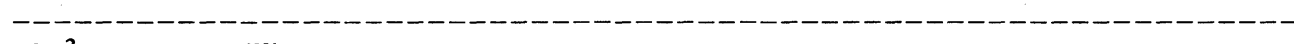 } \\
\hline $10^{-3}$ & milli & $\mathbf{m}$ & \\
\hline $10^{-6}$ & micro & $\mu$ & \\
\hline $10^{-9}$ & nano & n & \\
\hline $10^{-12}$ & pico & $\mathbf{p}$ & \\
\hline $10^{-15}$ & femto & f & \\
\hline $10^{-18}$ & atto & $\mathbf{a}$ & \\
\hline
\end{tabular}


3.10. Derived coherent unit: unit constructed from base units, exclusively. Examples: mole per kilogram, kilogram per cubic metre.

Note: Kinds of quantities having the dimension one use the coherent unit 'unity' (1).

3.11. Derived non-coherent unit: unit constructed from base units and numerical factors, which may be named and symbolized (see 3.12). Examples: milligram, mole per litre.

3.12. Factors for units: These factors which are part of the SI [12], create multiples of units and are often called by a name used as a prefix or a letter symbol before the unit symbol. Examples: megametre $(\mathrm{Mm})$ for $10^{6}$ metre, micrometre $(\mu \mathrm{m})$ for $10^{-6}$ metre; see Table II (3.12).

Note 1. The twelve prefixes above the upper and below the lower broken lines in the table are especially recommended by CQUCC and EPQU because the systematic use of factors that are powers of ten with exponents that are simple multiples of three facilitates conversion procedures for results in different units.

Note 2. These prefixes may not stand alone and must not be used together with the unit 'unity' (1), employed by quantities having the dimension one (cf. 3.10, Note). This is not practical and could be solved by designating a name and symbol to 'unity'.

\section{Kinds of quantities and units}

4.0. Only the most necessary information is given in connection with each kind of quantity: name, (type), symbol, and in some cases an identifying definition; the unit name, (type), symbol, and sometimes a definition. The abbreviations for type of kind of quantity and for unit are explained in Table III (4.0).

4.0.1. The italic symbols for a number of intensive kinds of quantities do not carry a subscript indicating the component; e.g. the former $c_{B}$ for 'substance

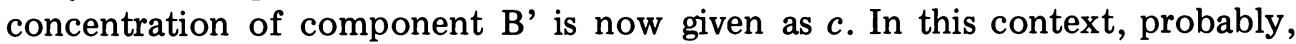
only mass density and mass concentration may be confused as both are symbolized $\rho$. When necessary, mass concentration is symbolized $\rho_{\mathbf{B}}$ or $\rho(\mathrm{B})$; other kinds of quantities may be specified analogously.

Recommended types of symbols for subunits and some corresponding forms that are not recommended [in brackets] are listed. Examples are given in Section 7, with codes and abbreviations explained in Tables IV (7.3) and V (7.5).

TABLE III (4.0)

CODES USED IN SECTIONS 4 AND 6

\begin{tabular}{ll}
\hline Code & Meaning \\
\hline B & Base \\
D & Derived \\
DC & Derived coherent \\
DnC & Derived non-coherent \\
spec C & Special coherent \\
\hline
\end{tabular}


4.1

$\begin{array}{ll}\text { Length (B) } & l \\ \text { Metre (B) } & \mathrm{m} \\ \mathrm{m} & {[\mathrm{cm}] *} \\ \mathrm{~mm} & {[\mu, \mathrm{u}]} \\ \mu \mathrm{m} & {[\mathrm{m} \mu, \mathrm{mu}]}\end{array}$

Note 1. The spelling 'metre' is recommended in English [12]. The American form is 'meter'.

Note 2. The order of magnitude changes by a factor of $10^{-3}$ between successive units listed.

\section{2}

Area (D)

$A$

Square metre (DC) $\mathrm{m}^{2}$

$\mathrm{m}^{2}$

$\mathrm{mm}^{2}$

$\left[\mathrm{cm}^{2}\right] *$

$\mu \mathrm{m}^{2}$ $\left[\mu^{2}\right] *$

Note. The order of magnitude changes by a factor of $10^{-6}$ between successive units listed.

\section{3}

\begin{tabular}{lll}
$\begin{array}{l}\text { Volume (D) } \\
\text { Litre (DnC) } \\
\text { Cubic }\end{array}$ & \multicolumn{1}{l}{$\begin{array}{l}\text { metre (DC) } \\
\mathrm{m}^{3}\end{array}$} & $\mathrm{~m}^{3}$ \\
$\mathrm{l}$ & {$\left[\mathrm{dm}^{3}\right]$} & {$[\mathrm{L}, \mathrm{l}] *,. * *$} \\
& & {$[\mathrm{dl}]$} \\
$\mathrm{ml}$ & {$\left[\mathrm{cm}^{3}\right]$} & {$[\mathrm{cc}, \mathrm{ccm}]$} \\
$\mu l$ & $\mathrm{~mm}^{3}$ & {$[\lambda, \mathrm{ul}]$} \\
$\mathrm{nl}$ & & \\
$\mathrm{pl}$ & & {$[\mu \mu \mathrm{l}, \mathrm{uul}]$} \\
$\mathrm{fl}$ & $\mu \mathrm{m}^{3}$ & {$\left[\mu^{3}, \mathrm{u}^{3}\right]$}
\end{tabular}

Note 1. The litre has been redefined (CGPM, 1964) and is now exactly equal to the cubic decimetre.

Note 2. CQUCC has decided to retain the litre as a permissible unit, especially because of the convenience of its multiples $(\mathrm{ml}, \mu \mathrm{l}$, etc.) and its continued use in chemistry. This decision has become 'respectable' because the International Committee of Weights and Measures (CIPM) has recognized [12] that the litre and a few other units 'play such an important part that they must be retained for general use with the International System of Units'. The preference of litre is supported jointly by a 1972 Recommendation from ICSH, IFCC, and WAPS [6]. An eventual choice of 'cubic metre' as preferred unit in practice would not change the significant figures: $1,037 \mathrm{l}=1,037 \times 10^{-3} \mathrm{~m}^{3}\left(=1,037 \mathrm{dm}^{3}\right)$.

Note 3. The 'litre' and the numeral 'one' should be given distinctly different symbols: 1 and 1 respectively.

* Symbols in square brackets are not recommended.

** IUPAC and Comité International des Poids et Mesures recently have approved ' $L$ ' as an alternative symbol for 'itre'. 
Note 4. The order of magnitude changes by a factor of $10^{-9}$ for each step of the series $\mathrm{m}^{3}, \mathrm{~mm}^{3}, \mu \mathrm{m}^{3}$.

\section{4}

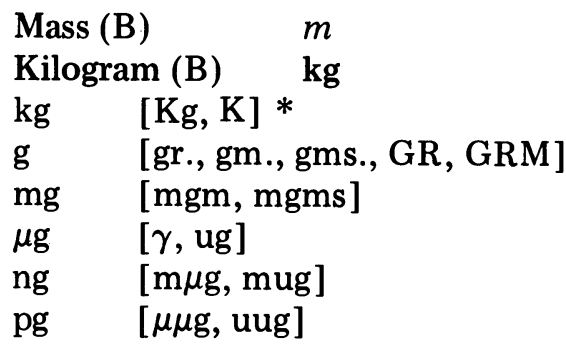

Note 1. The spelling 'kilogram' is recommended [12] in American and English.

Note 2. 'Mass' should not be confused with 'weight' which is a derived kind of quantity. (The dimensions are $\mathrm{M}$ and $\mathrm{LMT}^{-2}$ respectively.)

\section{5}

Number (of entities) (D) $\quad N$

Unity (DC) 1

$\times 10^{9}, \times 10^{6}, \times 10^{3}, \times 1, \times 10^{-3}$

Note 1. This kind of quantity has the dimension one (see 3.8 and 3.4 , Note 1) and the coherent unit is 'unity' (1).

Note 2. This kind of quantity was called 'number of particles' in QU-R66-4.5.

4.6

Amount of substance (B) $n$

Mole (B) mol

mol [M, $M$, eq, val, g-mol] *

mmol [mM, meq, mval]

$\mu \mathrm{mol} \quad[\mu \mathrm{M}, \mathrm{uM}, \mu \mathrm{eq}, \mu \mathrm{val}]$

nmol [nM, neq, nval]

Note 1. SCC and IFCC recommend that kinds of quantities of a 'molecular' nature should be used whenever an elementary entity can be stated for a component, be it electrolyte or non-electrolyte, inorganic or organic (see 2.12).

Note 2. 'Amount of substance' supplants the ambiguous concept 'equivalent amount'. The elementary entity (see 2.10) forming the basis of measurement should be indicated whenever doubt may arise. Thus 'Calcium(II) ion(Ca)' would indicate unchelated divalent ionized calcium with oxidation number +II, i.e. $\mathrm{Ca}(\mathrm{II})^{2+}$. The component having the entity half as large would be 'Calcium(II) ion $\left(\mathrm{Ca}_{0.5}\right)$ ' or 'Calcium(II) ion $\left(\mathrm{Ca}_{0.5}^{2+}\right)$ ' or 'Calcium(II) ion( $\left.\frac{1}{2} \mathrm{Ca}\right)$ ' (see [10], Section 3.6).

Note 3. The unit 'mole' is the amount of substance of a system which contains as many elementary entities as there are atoms in 0,012 kilogram of carbon-12. When the mole is used, the elementary entities must be specified and may be atoms, molecules, ions, electrons, other particles, or specified groups of such particles.

Note 4. The mole is an amount of substance and is not a number of elemen-

* Symbols in scuare brackets are not recommended. 
tary entities. However, the amount of substance constituting one mole contains about $0,6022045 \times 10^{24}$ elementary entities.

4.7

$\begin{array}{lll}\begin{array}{l}\text { Catalytic activity (D) } \\ \text { Katal (special DC) } \\ \text { (Mole per second (DC)) }\end{array} & \begin{array}{l}z \\ \text { kat } \\ (\mathrm{mol} / \mathrm{s})\end{array} \\ \text { kkat } & (\mathrm{kmol} / \mathrm{s}) & \\ \text { kat } & (\mathrm{mol} / \mathrm{s}) & \\ \text { mkat } & (\mathrm{mmol} / \mathrm{s}) & {[\mathrm{kU}] *} \\ \mu \text { kat } & (\mu \mathrm{mol} / \mathrm{s}) & {[\mathrm{U}]} \\ \text { nkat } & (\mathrm{nmol} / \mathrm{s}) & {[\mathrm{mU}]}\end{array}$

Note 1. Catalytic activity of an enzyme is a property measured by the catalysed rate of reaction of a specified chemical reaction, produced in a specified assay system.

Note 2 . The catalysed rate of reaction, proposed symbol $\dot{\xi}_{\text {cat }}$, is defined as the observed rate of reaction, $\dot{\xi}$, minus the spontaneous rate of reaction, $\dot{\xi}_{0}$, observed under otherwise similar conditions in the absence of added catalytic material. The rate of reaction $(\dot{\xi})$ is defined [10] as the rate of increase of the extent of reaction $(\xi)$

$\dot{\xi}=\mathrm{d} \xi / \mathrm{d} t=\nu_{\mathrm{B}}^{-1} \cdot \mathrm{d} n_{\mathrm{B}} / \mathrm{d} t$

where $\nu_{\mathrm{B}}$ is the stoichiometric coefficient of component $\mathrm{B}$ in the chemical equation for the reaction; $\nu_{\mathrm{B}}$ is assigned a negative value if $\mathrm{B}$ is a reactant and a positive value if $B$ is a product. The rate of reaction so defined has the same value whichever participant $B$ is selected for measurement (in contrast to the rate of change in the amount of substance of component $B$ itself, $\mathrm{d} n_{\mathrm{B}} / \mathrm{d} t$ ).

Note 3 . The catalysed rate of reaction pertains to a reaction in a specified assay system, whereas catalytic activity is considered to be a property of the enzyme, characterizing it even when it is not being tested in the assay system. Catalytic activity is proportional to the (usually unknown) amount of substance of the catalytic component in the material or preparation of interest.

Note 4. Catalytic activity, being defined as equal to (catalysed) rate of reaction, is of the same dimension $\left(\mathrm{NT}^{-1}\right)$, and is measured in the same SI derived unit 'mole per second'. The special name 'katal' and symbol 'kat' have been proposed by clinical chemists [4,14] and biochemists [2] for this unit in the context of measured catalytic activity. EPQU and Expert Panel on Enzymes have asked IFCC to request CGPM to consider official approval of such use. IUPAC and IUB are expected to support the presentation. CQUCC and EPQU, meanwhile, provisionally recommend that katal and kat be employed in the specific context of catalytic activities measured in medicine.

Note 5. The unit 'katal' is independent of assay conditions, although the measured catalytic activity of a certain system depends on assay conditions. By analogy, the unit metre is constant whereas the length of an iron bar depends on temperature.

\footnotetext{
* Symbols in square brackets are not recommended.
} 
Note 6. The term 'catalytic activity' is preferred to such terms in previous use (and somewhat differently defined) as 'catalytic amount' [4] and 'enzymic activity' [2]. It should be emphasized that results for catalytic activity imply reference to specified conditions of assay.

Note 7. Values obtained by one method may sometimes be converted to those of another method by means of an empirical factor; great caution should be exerted on account of unknown accelerators, inhibitors, and different effects on the individual enzymes in a mixture. In fact, different methods imply different quantities. Conversion is therefore merely an example of the general problem of converting the value of one quantity to that of another by regression analysis.

Note 8. The use of the 'enzyme unit' (symbol U) $=1 \mu \mathrm{mol} / \mathrm{min}$ [9] should be discontinued [2]. For any method of assay $1 \mathrm{U}=1 \mu \mathrm{mol} / \mathrm{min}=16,67 \mathrm{nmol} / \mathrm{s}$ $=16,67$ nkat.

\section{8}

Mass concentration (D) $\rho$

Kilogram per litre $(\mathrm{DnC}) \quad \mathrm{kg} / \mathrm{l}$

$\mathrm{kg} / \mathrm{l} \quad[\mathrm{g} / \mathrm{ml}] *$

$[\%, \mathrm{~g} \%, \%(\mathrm{w} / \mathrm{v}), \mathrm{g} / 100 \mathrm{ml}, \mathrm{g} / \mathrm{dl}]$

$\mathrm{g} / \mathrm{l} \quad[\% o, \mathrm{~g} \%$ o, $\%$ o(w/v) $]$

[mg\%, mg\%(w/v), mg/100 ml, mg/dl]

$\mathrm{mg} / \mathrm{l} \quad$ [ppm, p.p.m.(w/v), mg\%o]

$[\mu \mathrm{g} \%, \mu \mathrm{g} \%(\mathrm{w} / \mathrm{v}), \mu \mathrm{g} / 100 \mathrm{ml}, \mathrm{ug} / \mathrm{dl}]$

$\mu \mathrm{g} / \mathrm{l}$

$\mathrm{ng} / \mathrm{l} \quad[\mu \mu \mathrm{g} / \mathrm{ml}, \mathrm{uug} / \mathrm{ml}]$

Note 1. This kind of quantity is the mass of the component divided by the volume of the system.

Note 2. The coherent unit is 'kilogram per cubic metre', see 4.3 , Note 2 . The use of this unit does not change the significant figures or the position of the decimal sign: $0,37 \mathrm{mg} / \mathrm{l}=0,37 \times 10^{-3} \mathrm{~kg} / \mathrm{m}^{3}$.

Note 3: Use of different volume bases, e.g. microlitre, millilitre, 100 millilitres, and litre is discouraged. Only the litre should be used.

Note 4. The symbols \%, \%o, and p.p.m. are incorrect and ambiguous.

Note 5. Components for which elementary entities can be designated, preferably are measured according to 4.11 .

4.9

Mass fraction (D) $w$

Unity (DC) $\quad 1$

X

$$
x
$$

$\times 10^{-3} \quad[\mathrm{~g} / \mathrm{kg}]$

$\times 10^{-6} \quad[\mathrm{mg} / \mathrm{kg}]$

$\times 10^{-9} \quad[\mu \mathrm{g} / \mathrm{kg}]$

$\times 10^{-12} \quad[\mathrm{ng} / \mathrm{kg}]$

$$
\begin{aligned}
& {[\mathrm{g} / \mathrm{g}] *} \\
& {[\%, \%(\mathrm{w} / \mathrm{w})]} \\
& {[\% o, \% o(w / w)]} \\
& {[p . p . m ., \text { p.p.m.(w/w), ppm] }} \\
& {[\text { p.p.b., p.p.b.(w/w), ppb] }}
\end{aligned}
$$

* Symbols in square brackets are not recommended. 
Note 1. This kind of quantity is the mass of the component divided by the mass of the system.

Note 2. This kind of quantity has the dimension one (see 3.8 and 3.4, Note 1 ) and the coherent unit is 'unity' (1). The unit 'kilogram per kilogram' is a redundant alternative.

Note 3. Owing to the indiscriminate and ambiguous use of per cent (\%), per mille (\%o), parts per million (p.p.m.), and parts per billion (p.p.b.) these units should be abandoned.

Note 4. Components for which elementary entities can be designated, preferably are measured according to 4.13 .

4.10

Volume fraction (D)

Unity (DC)

$\times 1$

$[1 / 1]$

$\varphi$

$[\%, \%(\mathrm{v} / \mathrm{v})$, vol\%]

$\times 10^{-3} \quad[\mathrm{ml} / \mathrm{l}] \quad[\%, \% o(\mathrm{v} / \mathrm{v}), \mathrm{vol} \% \mathrm{o}]$

$\times 10^{-6} \quad[\mu \mathrm{l} / \mathrm{l}] \quad[$ p.p.m., p.p.m.(v/v), ppm]

Note 1. This kind of quantity is the volume of the isolated component divided by the volume of the system, both volumes at specified conditions.

Note 2. This kind of quantity has the dimension one (see 3.8 and 3.4, Note 1) and the coherent unit is 'unity' (1). The unit 'litre per litre' (or the derived coherent unit 'cubic metre per cubic metre') are redundant alternatives.

Note 3. As 4.9, Note 3.

Note 4. As 4.9, Note 4 and 4.11.

Note 5. Giving dilution 'strength' as $1: 2,2: 3$, etc. is ambiguous. The use of 4.10 or a precise description of the procedure is recommended.

4.11

Substance concentration (D) $\quad c$

Mole per litre $(\mathrm{DnC}) \quad \mathrm{mol} / \mathrm{l}$

$\mathrm{mol} / \mathrm{l} \quad[\mathrm{M}, M, \mathrm{eq} / \mathrm{l}, \mathrm{val} / \mathrm{l}, \mathrm{N}, N, \mathrm{n}] *$

$\mathrm{mmol} / \mathrm{l} \quad[\mathrm{mM}, \mathrm{m} M, \mathrm{meq} / \mathrm{l}, \mathrm{mval} / \mathrm{l}$, etc. $]$

$\mu \mathrm{mol} / \mathrm{l} \quad[\mu \mathrm{M}, \mathrm{uM}, \mu \mathrm{eq} / \mathrm{l}, \mathrm{etc}$.

$\mathrm{nmol} / \mathrm{l} \quad[\mathrm{nM}, \mathrm{neq} / \mathrm{l}$, etc.]

Note 1. This kind of quantity is the amount of substance of the component divided by the volume of the system. The elementary entity of the component should be stated, if doubt may occur.

Note 2. The importance of this kind of quantity should appear from 4.6, Note 1. An alternative is 4.13 .

Note 3. Concerning the concept 'equivalent concentration', see the analogous 4.6, Note 2.

Note 4. The derived coherent unit is 'mole per cubic metre', see 4.3 , Notes $1-4$, and 4.8 , Note 2 .

Note 5 . Concerning the volume base, see 4.8 , Note 3 .

Note 6. In QU-R66 the name 'molar concentration' was used, but the term 'molar' is now restricted by IUPAC to kinds of quantities having in their defi-

* Symbols in square brackets are not recommended. 
nitions 'an extensive kind of quantity of the system divided by amount of substance of the system'. The internationally recommended term for the kind of quantity defined in Note 1 is 'concentration' or 'amount of substance concentration'. After discussions (1971) with IUPAC Commission I.1 it was agreed that CQUCC can recommend the name 'substance concentration' to avoid confusion with the word 'concentration' in the colloquial sense.

4.12

Molality (D) $m$

Mole per kilogram (DC) $\mathrm{mol} / \mathrm{kg}$

$\mathrm{mol} / \mathrm{kg} \quad[\mathrm{m}, \mathrm{m}, \mathrm{mmol} / \mathrm{g}, \mu \mathrm{mol} / \mathrm{mg}] *$

$\mathrm{mmol} / \mathrm{kg} \quad[\mathrm{mm}, \mathrm{mm}]$

$\mu \mathrm{mol} / \mathrm{kg} \quad[\mu \mathrm{m}, \mu \mathrm{m}]$

Note 1. This kind of quantity is the amount of substance of the component in the solution divided by the mass of the solvent. The elementary entity of the solute should be stated, if doubt may arise.

Note 2. For another possibility, see 4.13.

Note 3. The kilogram is preferred as denominator in the units.

4.13

Substance fraction (D) or mole fraction (D) $x$

Unity (DC)

X1 $[\mathrm{mol} / \mathrm{mol}] *$

1

$\begin{array}{lll}\times 10^{-3} & {[\mathrm{mmol} / \mathrm{mol}]} & {[\%, \mathrm{~mol} \%]} \\ \times 10^{-6} & {[\mu \mathrm{mol} / \mathrm{mol}]} & \end{array}$

Note 1. This kind of quantity is the amount of substance of the component divided by the amount of substance of all components in the system. The elementary entities of the components should be stated, if doubt may arise.

Note 2. This kind of quantity has the dimension one (see 3.8 and 3.4, Note 1 ) and the derived coherent unit is 'unity' (1). The unit 'mole per mole' is a redundant alternative.

Note 3. As 4.9, Note 3 .

Note 4. In QU-R66 the name for this kind of quantity was 'mole fraction', and this, still, is the IUPAC and ISO name; however, the name of a unit does not belong in the kind-of-quantity name and CQUCC and EPQU, therefore, suggest the designation 'substance fraction'. The fully systematic name is 'amount-of-substance fraction'.

\subsection{4}

Number concentration (D) $\quad C$

One per litre $(\mathrm{DnC})$

$\times 10^{9} / 1 \quad \times 10^{9} 1^{-1}$

$\times 10^{6} / 1 \quad \times 10^{9} 1^{-1}$

$\times 10^{3} / 1 \quad \times 10^{3} 1^{-1}$

$\times 1 / 1 \quad 1^{-1}$

$\times 10^{-3} / 1 \quad \times 10^{-3} 1^{-}$

$$
\begin{aligned}
& C \\
& 1^{-1} \text { or } 1 / 1
\end{aligned}
$$

$\left[\times 1 / \mu \mathrm{l}, \mathrm{X} 1 / \mathrm{ul}, \mu \mathrm{l}^{-1}\right] *$

$\left[\times 1 / \mathrm{ml}, \mathrm{ml}^{-1}\right]$

* Symbols in square brackets are not recommended. 
Note 1. This kind of quantity is the number of stated particles or elementary entities of the component divided by the volume of the system.

Note 2. The unit 'one per litre' is preferred to 'one per millilitre' and 'one per microlitre'.

Note 3. The derived coherent unit is 'one per cubic metre', see 4.3 , Notes $1-4$, and $23 \times 10^{3} / 1=23 \times 10^{6} / \mathrm{m}^{3}$.

Note 4. This kind of quantity had the too restrictive name 'particle concentration' in QU-R66-4.14.

4.15

Number fraction (D) $\delta$

Unity (DC) 1

$\times 1$

$\begin{array}{ll} & {[\%] *} \\ \times 10^{-3} & {[\% 0]}\end{array}$

$\times 10^{-6}$

Note 1. This kind of quantity is the number of defined particles or elementary entities constituting the specified component divided by the total number of defined particles in the system.

Note 2. This kind of quantity has the dimension one (see 3.8 and 3.4 , Note 1 ) and the coherent unit is 'unity' (1).

Note 3. As 4.9, Note 3.

Note 4. This kind of quantity had the too restrictive name 'particle fraction' in QU-R66-4.15.

\subsection{6}

Catalytic activity concentration (D) $\quad b$

Katal per litre (special DnC)

(Mole per second litre)

$\begin{array}{lll}\text { kkat } / 1 & \left(\mathrm{kmol} \cdot \mathrm{s}^{-1} \cdot \mathrm{l}^{-1}\right) & {[\mathrm{kmol} / \mathrm{s} / \mathrm{l}] *} \\ \mathrm{~kat} / \mathrm{l} & \left(\mathrm{mol} \cdot \mathrm{s}^{-1} \cdot \mathrm{l}^{-1}\right) & {[\mathrm{mol} / \mathrm{s} / \mathrm{l}]} \\ \mathrm{mkat} / 1 & \left(\mathrm{mmol} \cdot \mathrm{s}^{-1} \cdot \mathrm{l}^{-1}\right) & {[\mathrm{mmol} / \mathrm{s} / 1]} \\ \mu \mathrm{Ukat} / \mathrm{l} & \left(\mu \mathrm{mol} \cdot \mathrm{s}^{-1} \cdot \mathrm{l}^{-1}\right) & {[\mathrm{U} / \mathrm{ml}]} \\ & & {[\mathrm{U} / \mathrm{l}]}\end{array}$

$b$

kat/l

$\left(\mathrm{mol} \cdot \mathrm{s}^{-1} \cdot \mathrm{l}^{-1}\right)$

Note 1. This kind of quantity is the catalytic activity of the component (enzyme) divided by the volume of the system.

Note 2. The system mentioned in the definition is the original system containing the enzyme, not the assay system specified by method of measurement.

Note 3. CBN [2] recommends the name 'concentration of enzyme activity' for this kind of quantity, but has also considered the term 'catalytic activity concentration'. In actual practice, the term 'catalytic activity concentration' may be shortened to 'catalytic concentration'.

Note 4 . The coherent SI unit is 'mole per second cubic metre', but CQUCC recommends the use of the special derived non-coherent unit 'katal per litre',

* Symbols in square brackets are not recommended. 
in accordance with 4.3 , Notes $1-4,4.7$, Note 4 , and 4.8 , Note $2.1 \mathrm{~kat} / 1=$ $10^{3} \mathrm{~mol} \cdot \mathrm{s}^{-1} \cdot \mathrm{m}^{-3}$.

Note 5. The use of 'enzyme unit per millilitre' (symbol U/ml) should be discontinued; see 4.7 , Note $8.1 \mathrm{U} / \mathrm{ml}=16,67 \mu \mathrm{kat} / \mathrm{l}$.

Note 6. See also 4.7, Note 7.

\subsection{7}

Kinds of quantities of a relative nature (D)

Unity (DC)

$\times 1$

$\begin{array}{ll} & {[\%] *} \\ \times 10^{-3} & {[\% o]} \\ \times 10^{-6} & \text { [p.p.m., ppm] } \\ \times 10^{-9} & \text { [p.p.b., ppb] }\end{array}$

Note 1. Such a kind of quantity is a ratio between a kind of quantity referring to a specified system and an identical kind of quantity referring to another specified 'standard' or 'reference' system.

Note 2. This kind of quantity has the dimension one (see 3.8 and 3.4, Note 1 ) and the coherent unit is 'unity' (1).

Note 3. As 4.9, Note 3.

Note 4. Examples of this kind of quantity are 'relative length', 'relative substance concentration', and 'relative density' (see 4.25).

\subsection{8}

Thermodynamic temperature (B) $\quad T$

Kelvin (B)

$\mathrm{K} \quad\left[{ }^{\circ} \mathrm{K},{ }^{\circ}, \mathrm{K}^{\circ},{ }^{\circ} \mathrm{C}\right] *$

$\mathrm{mK}$

$\mathbf{K}$

Note 1. The prior name and symbol (as stated in QU-R66) were 'degree Kelvin' and ' $\mathrm{K}$ ' respectively. The new forms (kelvin and $\mathrm{K}$ ) were accepted at CGPM 1967.

Note 2. The unit is defined as the fraction $1 / 273,16$ of the thermodynamic temperature of the triple point of water.

\subsection{9}

Celsius temperature (D) $\quad \theta$

Degree Celsius (spec. D) ${ }^{\circ} \mathbf{C}$

${ }^{\circ} \mathrm{C}, \mathrm{K} \quad\left[\mathrm{C},{ }^{\circ}, \mathrm{C}^{\circ}\right.$, centigrade $] *$

$\mathrm{m}^{\circ} \mathrm{C}, \mathrm{mK}$

Note 1. The former name 'customary temperature' (as given in QU-R66) was changed to 'Celsius temperature' by CGPM 1967 . The symbol, $\theta$, is preferred over $t$ to avoid confusion with the same symbol for 'time'.

Note 2. The unit degree Celsius is identical with kelvin but is used only for Celcius temperatures $\theta$ defined by $\theta=T-273,15 \mathrm{~K}$ (exactly), where $T$ is thermodynamic temperature.

* Symbols in square brackets are not recommended. 
Note 3. As 'degree Celsius' is identical to 'kelvin', either may be used to record Celsius temperature; see also 4.20.

\subsection{0}

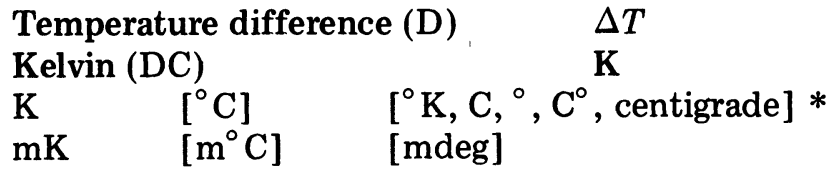

Note 1. The unit 'degree', symbolized 'deg' (as given in QU-R66), was abandoned by CGPM 1967.

Note 2. A temperature difference or temperature interval is preferably given in kelvins but can also be given in degrees Celsius.

\subsection{1}

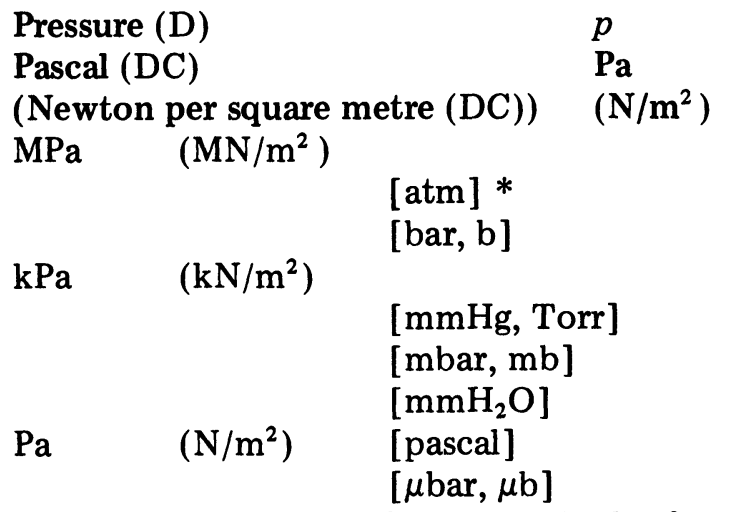

Note 1. This kind of quantity is the force (scalar value) at right angles to a plane divided by the area of that plane. (In physical chemistry, pressure could be defined as the negative value of the partial differential of the internal energy with respect to volume.)

Note 2. IUPAC has decided that the use of the unit 'bar' $\left(1 \mathrm{bar}=10^{5} \mathrm{~Pa}=\right.$ $10^{5} \mathrm{~N} / \mathrm{m}^{2}$ ) is to be progressively discouraged and CQUCC in 1969 decided that the use of bar (recommended in QU-R66) should no longer be recommended. It should be replaced by the derived SI coherent unit $\mathrm{Pa}$ (or $\left.\mathrm{N} / \mathrm{m}^{2}\right)$.

Note 3. Both 'pascal' $(\mathrm{Pa})$ and 'newton per square metre' $\left(\mathrm{N} / \mathrm{m}^{2}\right)$ are permitted derived coherent units, but $\mathrm{Pa}$ is preferred due to simplicity and to avoid duplicate names for the same unit.

Note 4. The unit 'newton' is the force that, when applied to a body having a mass of one kilogram, gives it an acceleration in vacuo of one metre per second squared.

Note 5. A measured liquid height requires correction for the temperature of the liquid and the local acceleration of free fall before conversion into any of the units of pressure.

* Symbols in square brackets are not recommended. 


\subsection{2}

Partial pressure (D)

Pascal (DC)

$p$

(Newton per square metre $(\mathrm{DC})) \quad\left(\mathrm{N} / \mathrm{m}^{2}\right)$

See 4.21 .

Note 1. This kind of quantity is defined as the product of the substance fraction of the gaseous component and the pressure of the gaseous system. Elementary entities should be given whenever doubt may arise.

Note 2. See 4.21, Notes 2-6.

Note 3. The tension of a gas in a liquid is much used by clinical chemists and physiologists and is generally understood as a kind of quantity yielding values equal to the partial pressure of the component in a gas phase in equilibrium with the same component dissolved in the liquid.

\subsection{3}

Time (B)

Second (B)

Minute (DnC)

Hour (DnC)

Day (24 hours) (DnC) d

Year (DnC)

Ms

a $\quad$ [yr.] $*$

ks

d [da.]

h [hr.]

$\mathrm{s}$

$\min$ [min., m]

[sec., s.]

$\mathrm{ms}$

$\mu \mathrm{s}$

[us]

Note 1. The unit 'second' permits a rational use of the decimal system. The unit 'hundredth of a minute' is discouraged; thus 0,15 min should be replaced by $9 \mathrm{~s}$.

Note 2. The designation 'time' should not be used for a specific point in a given calendar; the latter kind of quantity may be called 'calendar time'.

\subsection{4}

Mass density (D)

Kilogram per litre $(\mathrm{DnC}) \quad \mathrm{kg} / \mathrm{l}$

$\mathrm{kg} / \mathrm{l} \quad[\mathrm{g} / \mathrm{ml}] *$

$\mathrm{g} / \mathrm{l} \quad[\mathrm{mg} / \mathrm{ml}]$

$\mathrm{mg} / \mathrm{l} \quad[\mu \mathrm{g} / \mathrm{ml}]$

Note 1. This kind of quantity is the mass of a system divided by its volume.

Note 2. 'Mass density' should not be confused with 'weight density' ('specific weight') which is the weight of a system divided by its volume.

\footnotetext{
* Symbo' $;$ in square brackets are not recommended.
} 
Note 3. The derived coherent unit is 'kilogram per cubic metre', see 4.8, Note 2.

Note 4. The name 'density' for this kind of quantity is ambiguous because it is also used for 'relative density' (see 4.25) and 'absorbance' (also called 'optical density').

\subsection{5}

Relative density (D) $\quad d$

Unity (DC) 1

$\times 1$

$\times 10^{-3}$

Note 1 . This kind of quantity is the ratio between the density of the system and the density of a 'reference' or 'standard' system under conditions that should be specified for both systems.

Note 2. This kind of quantity has the dimension one and is an example of the group of kinds of quantities mentioned in 4.17.

Note 3. The term 'specific gravity', often used when water is the reference system, may be confused with 'specific weight'; see 4.24, Note 2 .

Note 4. A more rational name for 'relative density' would be 'relative mass density' and this name should be used in case of possible ambiguity.

\subsection{6}

Kinds of quantities of an arbitrary nature (non-SI B or D) International unit (non-SI B or D)

Arbitrary unit (non-SI B or D)

int. unit

arb. unit

[iu, u, IU, I.U.] *

Note 1. A kind of quantity of this nature with corresponding unit may be defined when the result of a measurement is not a part of a recognized kind of quantity having a definable dimension. An indication of method should form an integral part of the name for the kind of quantity. Anyone may define an arbitrary unit; the more authoritative 'international unit' is defined by an international body.

Note 2. Concerning 'titre', see QU-R66, 4.26.3.

Note 3. So-called 'qualitative measurements' and 'semiquantitative measurements' are simply 'quantitative' measurements with restricted modes of expression. The two types may be treated as arbitrary kinds of quantities and the results given as 0 or 1 arbitrary unit and $0,1,2,3, \ldots$ arbitrary units respectively. The symbols $-, \pm,(+),+,++$ etc. or $\div$ and $?$ are not recommended. The possible results may be stated as a specification to the kind of quantity (see Table VI (7.6), 4.26).

Note 4. Immunoglobulin $\mathrm{A}$ is a component for which the arbitrary amount of substance is recorded in international units. The value of a 'Blood-Sedimentation reaction' as arbitrary length(Westergren 1926) may be measured in arbitrary units.

\footnotetext{
* Symbols in square brackets are not recommended.
} 


\section{Printing rules for presentation of data}

5.1. Quantity names. The Recommendation 1966 states that a printed quantity name should be unambiguous and contain information on system (e.g. Serum), component (e.g. Sodium ion), and kind of quantity (e.g. substance concentration). The specific form may vary with language and local requirements. Some possibilities will appear from the list of examples in Section 7. For a more thorough discussion consult QU-R66, Parts 6 and 7, and 'List of Quantities. Approved Recommendation 1978'.

5.2. Printing rules for symbols of units and for numbers. The internationally recommended rules are given in QU-R66, 3.7.2-5 and 3.8; a few are repeated here.

5.2.1. Symbols for internationally recommended units should be printed in roman (upright) type, remain unaltered in the plural, and should be written without a final full stop. The symbols are in lower case letters, except, when derived from a proper name. Examples: The symbol for 'grams' is g, not g., gms., or $\mathrm{G}$.

5.2.2. The prefix name or symbol is printed in roman (upright) type as a prefix without a space before the name or symbol of the unmultiplied unit which may not be omitted. Compound prefixes are to be avoided when single prefixes are available; this also applies to the factor in the base unit 'kilogram'. Examples: milligram (mg), not milli gram (m g); micrometre $(\mu \mathrm{m})$, not micron $(\mu)$; picogram (pg), not micro-microgram $(\mu \mu \mathrm{g})$.

5.2.3. When a unit symbol carries an exponent, the factor is raised to the same power as the unmultiplied unit symbol. Examples: $1 \mathrm{~mm}^{2}=\left(10^{-3} \mathrm{~m}\right)^{2}=$ $10^{-6} \mathrm{~m}^{2} ; \mu \mathrm{l}^{-1}$ means $\left(10^{-6} \mathrm{l}\right)^{-1}$, not $10^{-6} \mathrm{l}^{-1}$.

5.2.4. The prefixes should not be used when the results are given for measurement of quantities having the dimension one, for which the coherent unit is 'unity' (1). Example: A mass fraction of $20 \times 10^{-3}$ or 0,020 should not be written $20 \mathrm{~m}$.

Note. One way of avoiding the bothersome powers of ten would be to create a name for the unit 1.

5.2.5. Products may be written $a b=a \cdot b=a \times b ; a^{n} b^{m} ; a^{n} \times b \times c^{p}$, etc. Quotients should be written

$$
\frac{a}{b}=a / b=a b^{-1}=a \times b^{-1} ; a b / c ; \frac{a / b}{c}=(a / b) / c=a \times b^{-1} \times c^{-1}=\frac{a}{b c}
$$

Note. In no case should more than one solidus (/) be employed in a given combination, except when the use of parentheses eliminates ambiguity; e.g. not $a / b / c$, but $(a / b) / c=a \times b^{-1} \times c^{-1}$ or $a /(b / c)=a \times b^{-1} \times c$ as the case may be.

5.2.6. The decimal sign is a comma on the line [7]. In documents in the English language a dot on the line can be used, but the comma is preferred in this Recommendation. If the absolute value of the number is less than one, a zero should precede the decimal sign. Numbers with many digits may be written with small spaces separating groups of three, counting from the decimal sign towards the left and right; a point or comma should not be used for separation. Example: 0,602 2045. 


\section{Proposed new derived kinds of quantities}

6.0. Development of new kinds of quantities. In QU-R66, Part 5, some useful kinds of quantities were proposed. Amendments were made by CQUCC in $1966,1971,1973$, and in 1976, and the results are briefly listed here. The abbreviations for type of kind of quantity and unit are explained in Table III (4.0).

\section{1}

Volume content (D) $\quad V_{\mathrm{c}} / m_{\mathrm{s}}$

Litre per kilogram $(\mathrm{DnC}) \quad \mathrm{l} / \mathrm{kg}$

Note 1. This kind of quantity is the volume of the (isolated) component (C) divided by the mass of the system (S). Example: Patient-Blood, volume content.

Note 2. The term 'content' is under discussion due to ambiguities.

Note 3. 'Volume content' should not be confused with 'specific volume', which is the volume of the system divided by the mass of the system.

\section{2}

Substance content (D) $\quad n_{\mathrm{c}} / m_{\mathrm{s}}$ Mole per kilogram (DC) $\mathrm{mol} / \mathrm{kg}$

Note 1. This kind of quantity is the amount of substance of the component divided by the mass of the system. (This kind of quantity should not be confused with 'molality', see 4.12.) Example: Liver-Glucose, substance content.

Note 2. See 6.1, Note 2.

\section{2 .1}

Catalytic activity content (D) $\quad z_{\mathrm{c}} / m_{\mathrm{s}}$

Katal per kilogram (DC) $\mathrm{kat} / \mathrm{kg}$

Note 1. This kind of quantity is the catalytic activity of the component divided by the mass of the system.

Note 2. See 6.1, Note 2.

\section{3}

$\begin{array}{ll}\text { Mean mass rate (D) } & \Delta m / \Delta t \\ \text { Kilogram per second (DC) } & \mathrm{kg} / \mathrm{s} \\ \text { Kilogram per day (DnC) } & \mathrm{kg} / \mathrm{d}\end{array}$

Note: This kind of quantity is the mass of the component changed in or moved to or from a system divided by the time during which the component was changed or moved.

\section{4}

Mean volume rate (D) $\Delta V / \Delta t$

Litre per second $(\mathrm{DnC}) \quad 1 / \mathrm{s}$

Litre per day (DnC) l/d

Note 1. As 6.3, Note, with substitution of 'volume' for 'mass'.

Note 2. The kind of quantity 'clearance' is usually defined as the product of the substance concentration of the component (or comparable derivative) in 
the specified output and the volume rate of that output divided by the substance concentration of the component in the specified input. Thus, this methodological definition equals 'mean volume rate' and this name is preferred.

\section{5}

Mean substance rate (D) $\Delta n / \Delta t$

Mole per second (DC) $\mathrm{mol} / \mathrm{s}$

Mole per day (DnC) $\mathrm{mol} / \mathrm{d}$

Note. As 6.3, Note, with substitution of 'amount of substance' for 'mass'. This kind of quantity usually should be preferred for mean mass rate (6.3) or mean volume rate $(6.4)$.

\section{6}

Mean catalytic activity rate (D) $\quad \Delta z / \Delta t$

Katal per second (DC) kat/s

Note. As 6.3, Note, with substitution of 'catalytic activity' for 'mass'. (This kind of quantity should not be confused with 'rate of reaction'.)

\section{7}

According to the latest views, the definitions given in QU-R66 for 'mass rate', 'volume rate', and 'mole rate' pertain to the kinds of quantities 'mean mass rate', 'mean volume rate', and 'mean substance rate' respectively. In daily practice these last three kinds of quantities are used. The definition of 'mass rate' would be: the rate of change in mass at a specified point in time of the component changed in or moved to or from a system. 'Volume rate' and 'substance rate' are defined analogously.

\section{Structure of quantity names}

7.1. As mentioned in 5.1, Recommendation 1966 states that printed quantity names should contain unambiguous information on system, component, and kind of quantity. The specific form may vary with language and purpose. The principle is now supported by a joint Recommendation 1972 of ICSH, IFCC, and WAPS [6]. For a thorough discussion of structure, see QU-R66, Parts 6 and 7. An abbreviated proposal for English names is given below.

7.2. Lists of names may be given for systems, components, and kinds of quantities respectively. A name for each specific quantity is constructed by selecting an appropriate item from each list. In this document, they are joined together in the following way: The name of the system, written with an initial capital letter, is followed by a long hyphen (em dash) -; the name of the component also begins with a capital letter, serves for primary alphabetizing, and is followed by a comma; finally comes the name of the kind of quantity, written in lower case letters. Names for systems and kinds of quantities may be abbreviated; for kinds of quantities their italicized symbols may also be used.

7.3. System. The name of the system, chosen as proper, stands alone. It may be preceded by an explanatory indication of a 'super' system or be followed by a 'sub' system. Examples: Blood, (Blood)Leukocytes, Patient(Urine). The full name is unambiguous, but possible codes in English for commonly used systems are given in Table IV (7.3). 
TABLE IV (7.3)

POSSIBLE CODES FOR SYSTEMS (IN ENGLISH)

\begin{tabular}{lll}
\hline Code & Meaning & Remark \\
\hline a & Arterial & (used as a prefix) \\
B & Blood & (used as a prefix) \\
c & Capillary & (used as a prefix) \\
d & 24-hour & \\
Ex & Expectoration & (or E) \\
Erc & Erythrocyte & (or (B)E) \\
(B)Erc & Erythrocyte (from blood) & (or Es) \\
Ercs & Erythrocytes & \\
fPt & Fasting patient & \\
F & Faeces & \\
Lkc & Leukocyte & \\
Lkcs & Leukocytes & \\
$\mathrm{P}$ & Plasma & \\
$\mathrm{Pt}$ & Patient & \\
S & Serum & (used as a prefix) \\
Sf & Spinal fluid & \\
U & Urine & \\
v & Venous & \\
\hline
\end{tabular}

7.4. Component. Usually, chemical names should conform with IUPAC nomenclature, whether the names be systematic or trivial. Elementary entities must be appended (in parentheses) when necessary to avoid ambiguity. Enzyme names should conform with IUPAC-IUB Recommendations 1972 [2]. Names

TABLE V (7.5)

ABBREVIATIONS FOR KINDS OF QUANTITIES

\begin{tabular}{ll}
\hline Abbreviation & Meaning \\
\hline ams. & Amount of substance \\
arb. & Arbitrary \\
cata. & Catalytic activity \\
catc. & Catalytic activity concentration \\
(cont. & Content) \\
dens. & Density \\
diff. & Difference \\
massc. & Mass concentration \\
massfr. & Mass fraction \\
molal. & Molality \\
substfr. & Substance fraction \\
numc. & Number concentration \\
numfr. & Number fraction \\
rel. & Relative \\
spec. & Specific \\
substc. & Substance concentration \\
temp. & Temperature \\
vol. & Volume \\
volfr. & Volume fraction \\
\hline
\end{tabular}


TABLE VI (7.6)

\section{EXAMPLES OF SYSTEMATIC QUANTITY NAMES}

\begin{tabular}{lll}
\hline $\begin{array}{l}\text { Cf. } \\
\text { Section }\end{array}$ & $\begin{array}{l}\text { Quantity } \\
\text { System-Component, kind of quantity }\end{array}$ & $\begin{array}{l}\text { Reference value } \\
\text { num. val. } \cdot \text { unit }\end{array}$ \\
\hline 4.16 & S-Acid phosphatase, catc.(Jacobsson 1960) & $=65 \mathrm{nkat} / \mathrm{l}$ \\
4.8 & S-Albumin, massc. & $=42 \mathrm{~g} / \mathrm{l}$ \\
4.9 & (S)Protein-Albumin, massfr.(method) & $=0,69$ \\
& & $=0,69 \mathrm{~kg} / \mathrm{kg}$ \\
4.11 & S-Albumin(68 000), substc. & $=618 \mu \mathrm{mol} / \mathrm{l}$ \\
4.11 & (fPt)S-Bilirubins, substc. & $=14 \mu \mathrm{mol} / \mathrm{l}$ \\
4.3 & Pt-Blood, vol. & $=4,901$ \\
4.6 & dU-Calcium(II), ams. & $=4,3 \mathrm{mmol}$ \\
4.11 & P-Carbonate + carbon dioxide, substc. & $=28 \mathrm{mmol} / 1$ \\
4.14 & Sf-Cells, numc. & $=2 \times 10^{6} / 1$ \\
4.23 & B-Coagulation, time(Biggs et al. 1957) & $=1,3 \mathrm{ks}$ \\
4.17 & fPt-Dioxygen(absorb.), rel. subst. rate(rest; Pt/Norm) & $=1,00$ \\
4.10 & B-Erythrocytes, volfr. & $=0,43$ \\
4.26 & U-Glucose, arb. substc. (Clinistix $\left.{ }^{\circledR} ; 0-1\right)$ & $=0 \mathrm{arb}$. unit \\
4.6 & (B)Erc(mean)-Hemoglobin $(\mathrm{Fe})$, ams. ${ }^{*}$ & $=2,0 \mathrm{fmol}$ \\
4.15 & (B)Lkcs-Lymphocytes, numfr. & $=0,3$ \\
4.4 & Pt-Patient, mass & $=70,8 \mathrm{~kg}$ \\
- & aB-Plasma, pH(37, $\left.{ }^{\circ} \mathrm{C}\right)$ & $=7,39$ \\
4.25 & B-Serum, rel. dens. $\left(\mathrm{S} .20{ }^{\circ} \mathrm{C} / \mathrm{H}_{2} \mathrm{O} 20^{\circ} \mathrm{C}\right)$ & $=1,026$
\end{tabular}

* Known as 'MCH' or 'mean cell hemoglobin'.

of methods should not supplant the component name, but, when necessary, should be placed in parentheses as an explanation after the name of the kind of quantity. Abbreviations should be avoided. Examples: Nitrogen(N), Calcium(II) ion(Ca), Calcium(II) ion( $\left.\mathrm{Ca}^{2+}\right)_{0,5}$ or Calcium(II) ion(positive charge), Fatty acid (carboxyl), Phosphate $(\mathrm{P})$, Chloride, Alanine-meaning the sum of negative, amphoionic, and positive particles-Alanine aminotransferase, Fluid(filtrated), e.g. from the renal glomeruli.

7.5. Kind of quantity. The names may be abbreviated as suggested in Table $\mathrm{V}$ (7.5) or given as their italicized symbols. Necessary specifications are placed in parentheses. Examples: relative substance concentration(Pt/Norm), viscosity $\left(4,0^{\circ} \mathrm{C}\right)$, cataly tic activity concentration(Kind and King 1954).

7.6. Systematic names. Examples of quantity names, constructed according to the above rules, are given in Table VI (7.6). They illustrate the use of different kinds of quantities and are mostly chosen to show a solution to the more difficult problems, rather than the easy. A presumably usual value is given, employing a recommended unit. For more (and often more simple) examples, see QU-R66, 7.3 and List of Quantities. Approved Recommendation 1978.

\section{References}

\footnotetext{
(Abbreviations on p. 2456)

1 Appendix to this document with list of Correspondence

2 Commission on Biochemical Nomenclature of the IUPAC and the IUB (1973) Enzyme Nomenclature. Recommendations (1972) on the Nomenclature and Classification of Enzymes together with their Units and the Symbols of Enzyme Kinetics, 443 pp., Elsevier, Amsterdam
} 
3 Commission on Quantities and Units in Clinical Chemistry of the IUPAC Section of Clinical Chemistry and Expert Panel on Quantities and Units of the IFCC Committee on Standards, Minutes Meeting Copenhagen 1972-06-16 to 17

4 Dybkaer, R. and Jфrgensen, K. (1967) Quantities and Units in Clinical Chemistry Including Recommendation 1966 of the Commission on Clinical Chemistry of the IUPAC and of the IFCC, $x+102$ pp., Munksgaard, Copenhagen

5 International Committee for Standardization in Hematology, Implications of IUPAC-IFCC Recommendations for Hematology, 17 pp., unpublished working document

6 International Committee for Standardization in Hematology, International Federation of Clinical Chemistry and World Association of (Anatomic and Clinical) Pathology Societies: Recommendation for Use of SI in Clinical Laboratory Measurements (1972). (See, e.g., (1973) Z. Klin. Chem. 11,93 (only))

7 International Organization for Standardization (ISO) (1973) General Introduction to ISO 31 . General Principles concerning Quantities, Units and Symbols, 14 pp., International Standard ISO 31/0

8 International Organization for Standardization (ISO) (1973) SI Units and Recommendations for the Use of their Multiples and of certain other Units, 1st edn., iii +21 pp., ISO 1000

9 International Union of Biochemistry (1965) Enzyme Nomenclature. Recommendations (1964) on the Nomenclature and Classification of Enzymes, together with their Units and the Symbols of Enzyme Kinetics, 219 pp., Elsevier, Amsterdam

10 International Union of Pure and Applied Chemistry, Division of Physical Chemistry, Commission on Symbols, Terminology, and Units (1970) Manual of Symbols and Terminology for Physicochemical Quantities and Units, 44 pp., Butterworths, London (also in (1970) Pure Appl. Chem. 21, 1-44)

11 McGlashan, M.L. (1971) Physicochemical Quantities and Units. The Grammar and Spelling of Physical Chemistry, 2nd ed., x 117 pp., The Royal Institute of Chemistry, London

12 National Physical Laboratory (1970) SI. The International System of Units, ix + 45 pp., Her Majesty's Stationery Office, London

13 IFCC, Committee on Standards, Expert Panel on Enzymes (1975) Provisional Recommendation (1974) on IFCC Methods for the Measurement of Catalytic Concentration of Enzymes. Clin. Chim. Acta 61, F11-F24, following p. 238

14 International Union of Pure and Applied Chemistry, Section on Clinical Chemistry, Commission on Quantities and Units in Clinical Chemistry and International Federation of Clinical Chemistry, Committee on Standards, Expert Panel on Quantities and Units (1974) Quantities and Units in Clinical Chemistry. Recommendation 1973. Pure Appl. Chem. 37, 517-546

15 Dybkær, R. (1978) Quantities and Units in Enzymology. Enzyme 22, 91-123

\section{Appendix}

Bergmeyer, H.U. (Tutzing, German Federal Republic)

British Association of Clinical Biochemists (Leeds, U.K.)

Broughton, P.M.G. (Leeds, U.K.)

Desaty, D. (Rexdale, Ontario, Canada)

Egger, E. (Berlin, German Democratic Republic)

Fischer, W. (Freiburg i.Br., German Federal Republic)

Harnoncourt, K. (Graz, Austria)

Herrmann, R. (Giessen, German Federal Republic)

Holtz, A.H. and van Assendelft, O.W. (ICSH Working Party on Quantities and Units) (Bilthoven, The Netherlands)

Jansen, A.P. (Nijmegen, The Netherlands)

Klingmüller, V. (Mannheim, German Federal Republic)

Laue, D. (Cologne, German Federal Republic)

Merten, D. (Jülich, German Federal Republic)

Narayanan, S. (Rutherford, New Jersey, U.S.A.)

New Units in Clinical Chemistry (Dutch Society of Clinical Chemistry) (Bilthoven, The Netherlands)

Rigg, J.C. (Wageningen, The Netherlands)

Riley, W.J. (Perth, Western Australia) 
Roth, M. (Geneva, Switzerland)

Schaffer, R. (Washington, D.C., U.S.A.)

Spitzer, R. (Vancouver, BC, Canada)

Tammisto, P. (Majalampi, Finland)

v. Boroviczény, K.-G. (Berlin, German Federal Republic)

Zender, R. (La Chaux-de-Fonds, Switzerland)

Keproduced from Clinica Chimica Acta, Vo1. 96 (1979),

pp. $157 \mathrm{~F}-183 \mathrm{~F}$ by courtesy of Elsevier North-Holland Biomedical

Press, Amsterdam. 